\title{
S. Linguagens \\ REFLEXÕES SOBRE O ENSINO E A APRENDIZAGEM DE LIBRAS A PARTIR DA EXPERIÊNCIA DOCENTE E DISCENTE NO CURSO DE LICENCIATURA
}

\author{
Amanda Maraschin Bruscato (UAIg - Portugal) \\ Andrea Maraschin Bruscato (UniRitter)
}

\begin{abstract}
RESUMO: Este artigo busca refletir sobre o ensino e aprendizagem da LIBRAS no curso superior a partir das experiências de uma professora universitária e aluna da licenciatura. Parte-se de uma reflexão sobre a cultura surda relacionada às conquistas legais e aos teóricos que vêm trabalhando sobre a temática, como Perlin (2004), Strobel (2008), Gesser (2009), entre outros. De acordo com o artigo $3^{\circ}$ do Decreto 5.626/2005, a LIBRAS passou a ser disciplina curricular obrigatória na formação dos professores. No entanto, percebe-se que em um semestre não há tempo suficiente para adquirir proficiência no idioma e preparar professores para alfabetizar pessoas surdas. $\mathrm{O}$ artigo conclui que, para garantir o direito à diversidade e a inclusão de pessoas surdas em classes orais, é necessário o comprometimento de todos - Estado, instituições educacionais, professores e sociedade em geral - para com a luta, respeito e educação da comunidade surda.
\end{abstract}

PALAVRAS-CHAVE: Cultura Surda. LIBRAS. Relato de experiência.

ABSTRACT: This paper aims to reflect on the teaching and learning of LIBRAS (Brazilian Sign Language) in higher education based on a professor's and an undergraduate student's experience. It starts with a reflection on deaf culture related to legal achievements and theorists who have been working on the subject, such as Perlin (2004), Strobel (2008), Gesser (2009), and others. According to the article 3 of the Decree 5.626/2005, LIBRAS became a compulsory curriculum subject in teachers' education. However, in one semester there is not enough time to acquire language proficiency and to prepare teachers to teach deaf people to read and write. The paper concludes that to guarantee the right to diversity and inclusion of deaf people in oral classes, the State, educational institutions, teachers and the whole society need to make a commitment to the fight, respect and education of deaf community.

KEYWORDS: Deaf Culture. LIBRAS. Brazilian Sign Language Experience Report.

\section{INTRODUÇÃO}

Há tempos que a comunidade surda tem se mobilizado e lutado pelo reconhecimento das condições linguísticas, culturais e educacionais dos surdos. Dentre as conquistas alcançadas, destaca-se a Lei 10.436/2002, que reconheceu a Língua Brasileira de Sinais LIBRAS - como meio de comunicação e expressão próprio da comunidade surda brasileira.

Entretanto, o Brasil ainda carece de pesquisas sobre o processo de ensino e aprendizagem da LIBRAS em sala de aula. Diante disso, após uma breve explicação sobre a 


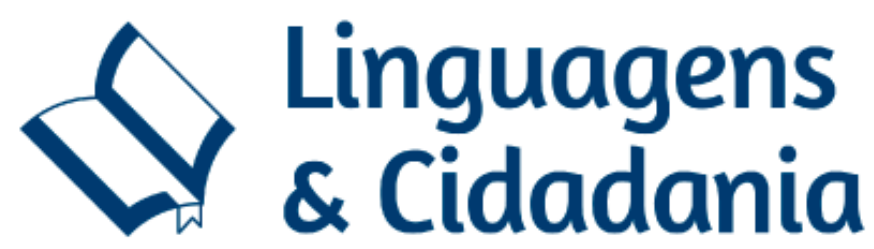

Língua Brasileira de Sinais e a luta pela conscientização da cultura surda, serão discutidos os desafios da docência em LIBRAS e a experiência de uma aluna da língua no ensino superior.

O panorama teórico sobre o estudo da língua partirá do livro de Audrei Gesser (2009) acerca da desmistificação de preconceitos e do desenvolvimento de uma maior consciência linguística. Após, será revista a luta pela conscientização da cultura surda em uma sociedade marcada pela oralização, em respeito à diversidade cultural. Por fim, serão apresentadas duas perspectivas sobre o ensino e a aprendizagem da Língua Brasileira de Sinais pela ótica de uma professora universitária e de uma aluna do curso de Pedagogia.

\section{A LÍNGUA BRASILEIRA DE SINAIS}

As línguas de sinais são como quaisquer outras línguas naturais e humanas, não havendo uma mais simples ou mais complexa que outra. É importante ressaltar que os sinais não são mímicas, não se ocupando em sinalizar a língua oral e nem em soletrar as palavras com as letras do alfabeto.

No Estruturalismo de Saussure (2006), os signos são formados por significados e significantes. Os signos da línguas de sinais não são exceção, servindo à teoria como quaisquer outras línguas. Os sinais, portanto, não se limitam a objetos, não se preocupam em ser icônicos. Por isso, os sinais não são gestos da forma como esta palavra é entendida nas línguas orais.

Da mesma forma que as línguas de sinais não são tentativas de mímica, o alfabeto tampouco é a língua. Ele apenas serve para soletrar as letras alfabéticas. Então, conhecer o alfabeto em LIBRAS não significa que se saiba LIBRAS.

A grande diferença das línguas de sinais para as outras línguas é que elas são gestualvisuais, ao invés de vocal-auditivas. E não há “a língua de sinais". O que há são línguas de sinais, cada uma com história e variação próprias.

Cada povo possui sua própria língua de sinais, não havendo a correspondência de uma língua de sinais para cada língua oral, e tampouco a língua de sinais de cada país surgiu de sua língua oral. A LIBRAS e a Língua de Sinais Americana (ASL), por exemplo, surgiram da Língua de Sinais Francesa. 


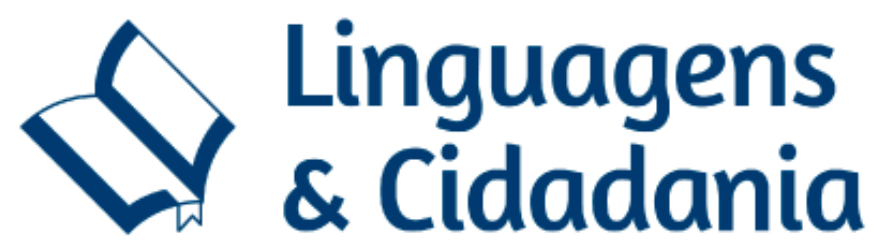

Para países de língua inglesa há mais de uma língua de sinais, sendo a Língua de Sinais Americana e a Língua de Sinais Britânica (BSL) bastante diferentes uma da outra. A ASL, por exemplo, utiliza apenas uma mão para cada letra do alfabeto. Já a BSL utiliza as duas mãos.

Ademais dessa diferença, as línguas variam entre seus próprios falantes. Não se pode esperar que alguém do Nordeste do Brasil utilize a mesma LIBRAS que alguém do Sul. A variação é um princípio comum a todas as línguas vivas, o que engloba línguas orais e de sinais.

Como todas as outras línguas, as línguas de sinais possuem gramática própria. Do mesmo modo que elas se encaixam no Estruturalismo, encaixam-se no Gerativismo de Chomsky (1975). Sendo assim, os surdos também possuiriam a Gramática Universal, gramática interna com que todos os seres humanos nasceriam e que se desenvolveria de acordo com o meio e devido à necessidade de comunicação. Inclusive, de acordo com Lyons (1987), o uso de sinais pelas mãos como forma de comunicação pelo homem é anterior ao da fala.

Na gramática das línguas de sinais também há fonologia, estudo que iniciou com Stokoe (1960). Os níveis fonológicos são as unidades mínimas das línguas, o que, no caso das línguas de sinais, são os parâmetros de configuração de mão (CM), o ponto de articulação (PA), o movimento $(\mathrm{M})$ e a orientação da palma da mão $(\mathrm{O})$, que servem para diferenciar os pares mínimos, aquelas palavras que apenas por uma unidade mínima são diferentes.

Segundo Ferreira-Brito (1995), nas línguas de sinais, as expressões faciais também são elementos gramaticais de extrema importância. Elas são necessárias nas línguas em geral, pois auxiliam no entendimento do que se quer comunicar, mas são consideradas traços paralinguísticos nas línguas orais.

Diferentemente das línguas orais, que possuem unidades lineares, nas línguas de sinais as unidades são simultâneas. Ou seja, enquanto os fonemas precisam ser pronunciados um após o outro, as unidades mínimas das línguas de sinais, mencionadas acima, são realizadas ao mesmo tempo. Como todas as outras línguas, elas também possuem produtividade/criatividade, flexibilidade, descontinuidade e arbitrariedade.

A escrita de sinais ainda está em processo, e certamente ajudará na emancipação linguística dos surdos.

\section{A LUTA PELA CONSCIENTIZAÇÃO DA CULTURA SURDA}




\section{Q Linguagens}

Os surdos são fisicamente e psicologicamente normais, podendo ser oralizados se quiserem. Eles não se consideram pessoas com deficiência e não são necessariamente mudos.

O problema é que a surdez é entendida patologicamente pelos médicos e, durante muito tempo, as línguas de sinais foram estigmatizadas e proibidas, forçando os surdos a serem oralizados independentemente de sua vontade e a buscarem o implante coclear como uma expectativa de cura. Suas línguas e culturas não eram valorizadas nem levadas em consideração.

A surdez pode ser genética, passando de pais para filhos, e tem distintos tipos e graus. Além disso, há a distinção entre surdos pré e pós-lingual, ou seja, entre os que nasceram surdos e os que adquiriram a surdez após aprenderem uma língua oral. O processo de alfabetização será, portanto, distinto dependendo de qual é a língua materna da criança.

Até hoje há o preconceito de que os surdos escrevem mal. Isso é consequência da falta de formação dos professores para alfabetizar as crianças surdas. A surdez não se relaciona com dificuldade intelectual, a questão aqui é a falta de preparo que os professores têm para acolher estes alunos.

A modalidade escrita que os surdos aprendem não é de sua própria língua. Sendo assim, o processo de alfabetização dos surdos não deveria ser o mesmo processo dos ouvintes. Afinal, para estes a questão é comunicar no papel aquilo que eles já comunicam oralmente. Para os outros, no entanto, é uma segunda língua, com gramática distinta da língua com que se comunica.

Segundo o Decreto $n^{\circ} 5626$ de 2005, baseado na Lei $n^{\circ} 10.436$ de 2002, a LIBRAS é língua oficial no país e deve ser inserida como disciplina curricular obrigatória nos cursos de formação de professores para o exercício do magistério em nível médio e superior. Dessa forma, o Decreto assegura dois fatos importantes: o primeiro é garantir que os surdos tenham seus direitos linguísticos cumpridos. Se temos duas línguas oficiais, todos os brasileiros, surdos ou ouvintes, deveriam aprender as duas línguas na escola através de um ensino bilíngue, sem que ocorresse a sobreposição de uma das línguas. O segundo é a formação de novos profissionais com conceitos acerca do surdo, da surdez e da língua de sinais. Portanto, todos os estudantes de Licenciaturas devem cursar LIBRAS como disciplina obrigatória. Então surge o dilema: é possível adquirir uma real proficiência no idioma em apenas um semestre? Teoricamente, todo professor formado está apto a dar aula para alunos surdos, assim como dar aula de LIBRAS para outros estudantes, o que não se comprova na prática. 


\section{W. Linguagens}

Nesse cenário atual, em que se privilegia o ensino de LIBRAS nos cursos de magistério e ensino superior, despontam indagações referentes ao processo de ensino, ao contexto educacional e a orientações metodológicas.

\section{OS DESAFIOS DA DOCÊNCIA EM LIBRAS}

Contribuir, enquanto professor universitário, com a formação de novos professores nos cursos de licenciatura, é um desafio e um privilégio na carreira docente. Primeiro, pela oportunidade em interagir com diferentes pessoas, seja em idades ou ideais; segundo, pelo desafio de crescimento a cada aula, buscando renovar e inovar os conhecimentos em educação. Como disse Paulo Freire,

\footnotetext{
Não há ensino sem pesquisa e pesquisa sem ensino [...] Enquanto ensino continuo buscando, reprocurando. Ensino porque busco, porque indaguei, porque indago e me indago. Pesquiso para constatar, constatando, intervenho, intervindo educo e me educo. Pesquiso para conhecer o que ainda não conheço e comunicar ou anunciar a novidade (FREIRE, 1997, p. 32).
}

Assim, busca-se refletir sobre as práticas pedagógicas, o que funciona e o que é preciso melhorar, atreladas às concepções de ensino e aprendizagem. Nesse processo, é fundamental a consciência da prática relacionada ao discurso teórico, visto que as concepções do professor acerca do ensino e da aprendizagem permeiam suas ações no contexto educacional (BARCELOS, 2006; TICKS, 2009).

Para um ouvinte, o primeiro desafio, enquanto professor da disciplina de LIBRAS, é creditar sua condição de professor da cultura surda, se está realmente apto para ensinar LIBRAS. Por se tratar de uma cultura específica, o surdo não seria a melhor escolha para divulgá-la? Afinal, a língua de sinais apresenta algumas particularidades que precisam ser consideradas no seu processo de ensino e aprendizagem e que requerem uma imersão em experiências visuais, produções manuais e performances corporais. Ela envolve habilidades de coordenação visual-motora, o que não é enfatizado no ensino das línguas orais. Além disso, para aprendizes ouvintes, se faz necessário o aprimoramento de um canal de comunicação espaço visual, no qual, muitas vezes, o oralizado apresenta dificuldades.

O segundo desafio é revelar que, em um semestre, os alunos não sairão proficientes em LIBRAS. Com certeza, isso já dá um desânimo nos discentes, que imaginam estar aptos em Linguagens \& Cidadania, v. 20, n. esp., jan./dez. 2018. 


\section{Q Linguagens}

língua de sinais ao final de 4 meses. Esquecem que levaram mais de um ano para aprender a falar. Segundo Vygotsky (1987), teórico amplamente estudado na licenciatura em pedagogia, será por volta dos 2 anos de idade que a fala da criança se tornará intelectual, com função simbólica mediada por significados construídos no meio cultural, ou seja, na interação com outras pessoas que já dispõe da linguagem estruturada.

O terceiro desafio é discutir, com os estudantes, o conceito de cultura surda. Sendo a turma, em sua maioria, ouvinte, relaciona o surdo como pessoa deficiente ou inválida. Para superar esse conceito, pode-se trabalhar com o significado de Strobel (2008, p. 24) sobre cultura surda:

A cultura surda é o jeito de o sujeito surdo entender o mundo e de modificá-lo a fim de se torná-lo acessível e habitável ajustando-os com as suas percepções visuais, que contribuem para a definição das identidades surdas e das "almas" das comunidades surdas. Isto significa que abrange a língua, as ideias, as crenças, os costumes e os hábitos de povo surdo.

De acordo com Perlin (2004), as identidades surdas são construídas dentro das representações possíveis da cultura surda, da sua luta política pelos direitos e da superação do caráter invalidez ou deficiente. Para os alunos ouvintes terem essa consciência, são propostas leituras e debates a respeito do tema. Também é feita a linha do tempo, vindo desde a Grécia Antiga, quando julgavam que o surdo, por não falar, não tinha pensamento, logo era incapaz de aprender; passando pela Idade Média até a contemporaneidade.

Alternando com os debates, procura-se ampliar, a cada aula, o aprendizado de vocabulários, seja através de exercícios de repetição, diálogo, dramatizações ou músicas. Os acadêmicos sentem-se desafiados e motivados quando precisam apresentar uma canção nova, com sinais que ainda não aprenderam. Também são apresentados canais de youtubers surdos, a fim de gerar debates sobre o assunto abordado. Assim, procura-se destacar os ideais e fragilidades da cultura surda, além de garantir que os estudantes desenvolvem a língua de sinais a partir de práticas sociais com enfoque comunicativo, refletindo sobre os contextos históricos e sociais vivenciados pelos surdos.

Um fator que muito contribui para o envolvimento dos acadêmicos nesse processo de ensino-aprendizagem são as oportunidades de comunicação, seja através de jogos em aula, das visitas em instituições específicas para surdos ou com convidados surdos. O ensino da LIBRAS a partir da proposta comunicativa aliado à adequação dos recursos metodológicos é fundamental 


\section{Winguagens}

para a aprendizagem da língua de sinais. Mas isso não minimiza os desafios da docência. Muito pelo contrário, indica que muito ainda deve ser feito para o reconhecimento e valorização da cultura surda.

O ensino de LIBRAS poderá redimensionar as relações entre surdos e ouvintes no momento em que transcende as questões linguísticas e contribui para a sociedade se constituir de maneira saudável, com respeito à diversidade. As práticas sociais mediadas pela língua propendem à formação de cidadãos críticos capazes de intervir na sociedade e proporcionam a todos os discentes acesso ao conhecimento e à aprendizagem.

\section{A EXPERIÊNCIA EM LIBRAS DE UMA ALUNA OUVINTE}

Como estudante de graduação, surgem grandes medos e expectativas para cursar a disciplina de LIBRAS. Afinal, o professor pode ser surdo, a turma pode não compreender a aula, o semestre pode não ser suficiente para proporcionar a comunicação em LIBRAS.

De fato, um semestre não é tempo suficiente para se tornar proficiente em uma língua que nunca se estudou antes. Aprende-se a cumprimentar alguém, pedir e responder informações pessoais, o básico para uma curta comunicação.

Obviamente, a turma não se torna tão rapidamente proficiente na língua. Mal conseguiria sustentar uma conversa com uma pessoa surda sem precisar recorrer a um dicionário de LIBRAS, a mímicas ou à soletração das palavras. E teria enormes dificuldades para alfabetizar um surdo.

No entanto, o semestre é de extrema importância para conscientizar aos envolvidos sobre a LIBRAS e a surdez no país. Pode-se entender mais sobre a língua e sua cultura, assim como a realidade e suas dificuldades.

Após os meses de leitura, encontros semanais e avaliações presenciais e a distância, surge o engajamento na luta pelos direitos linguísticos das pessoas surdas. Como futuros professores, é evidente a necessidade de mobilização para garantir que seus direitos sejam reconhecidos. É preciso buscar saber mais sobre o tema, compartilhar o que se sabe, conscientizar a população da necessidade de mudanças. Deve-se continuar estudando a LIBRAS, buscar entender o que a comunidade surda pede e planejar aulas inclusivas. 


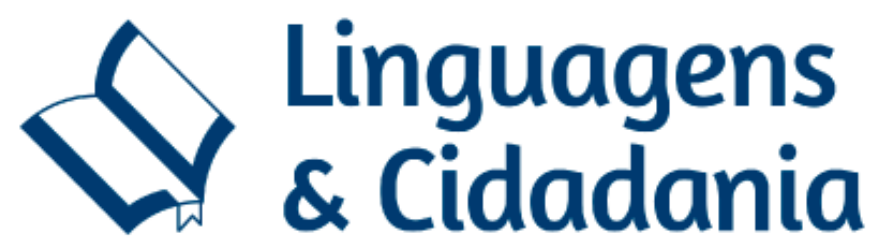

Conforme Marques (2017, p. 2117), "na formação do professor é preciso possibilitar mecanismos de construção de estratégias pedagógicas para viabilização da inclusão”. As aulas de LIBRAS utilizam distintas metodologias. Apesar de a repetição auxiliar na recordação dos sinais, o que parece mais contribuir para a aprendizagem são as atividades propostas para casa, como assistir ao filme E seu nome é Jonas, ler o livro de referência da disciplina, produzir um vídeo livre em LIBRAS e materiais para inclusão.

"Uma formação dialógica e consciente do papel do professor para cidadania inclusiva é uma construção contínua" (MARQUES, 2017, p. 2117), e, quando se confia na capacidade de o aluno buscar o conhecimento fora da sala de aula e se oferecem os meios necessários para isso, ele estará muito mais engajado no aprendizado, que também será mais significativo. Assim, os estudantes podem compartilhar informações novas de seu interesse e contagiar os outros pela vontade de aprender.

Na pesquisa para a gravação do vídeo, por exemplo, encontram-se diversos youtubers surdos brasileiros que podem auxiliar na decisão do que gravar e incentivam a buscar um maior conhecimento sobre a comunidade surda. Através da internet, tais canais são compartilhados com os colegas, que também passam a segui-los.

Em um semestre não é possível aprender tudo sobre algo, mas é possível aprender o básico e, o mais importante, aprender a buscar mais sobre o assunto. Afinal, cada um é responsável por sua própria formação, sendo o professor um mediador do processo de ensinoaprendizagem.

\section{CONSIDERAÇÕES FINAIS}

Este artigo procurou refletir sobre os desafios do ensino e aprendizagem de LIBRAS, a partir das experiências de professora e aluna do curso de Pedagogia. Viu-se que, apesar da trajetória educacional da cultura surda no Brasil e dos avanços nos aspectos legais que determinam a obrigatoriedade de LIBRAS, o cenário ainda é bastante discreto.

As decisões acordadas após a promulgação da Lei 10.436/2002 e do Decreto 5.626/2005 mostram que existem avanços em relação à formação dos professores, mas que um semestre ainda é insuficiente para garantia do bilinguismo. Nesse contexto, os maiores prejudicados são 


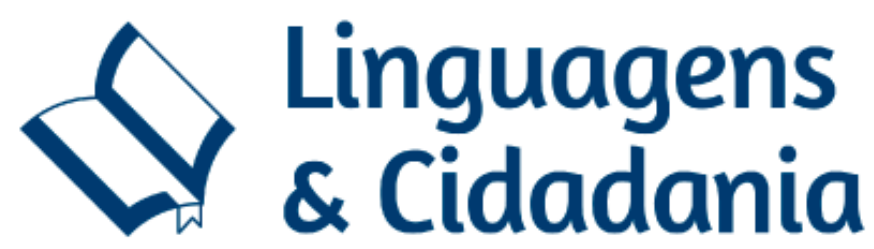

os surdos, pela falta de uma educação bilíngue que aproxime as comunidades surdas e ouvintes, minimizando as diferenças educacionais, linguísticas, políticas e sociais.

A aproximação dos aspectos culturais da comunidade surda é fundamental para o entendimento de quem é o surdo e de qual sua forma de comunicar-se. Ademais, as metodologias e estratégias de comunicação devem ser variadas e dinâmicas, de forma a facilitar o processo de ensino-aprendizagem de LIBRAS. Do mesmo modo, os docentes devem continuar investindo em sua formação, qualificando o ensino da língua como um processo educativo, de forma a colaborar para a formação social e educacional do ser humano.

\section{REFERÊNCIAS}

BARCELOS, A. M. F. Cognição de professores e alunos: Tendências recentes na pesquisa de crenças sobre ensino e aprendizagem de línguas. In: BARCELOS, A. M. F.; VIEIRA ABRAHÃO. M. H. (Org.). Crenças e ensino de línguas: Foco no professor, no aluno e na formação de professores. Campinas, SP: Pontes, 2006. p. 15-42.

BRASIL. Lei n. 10.436 de 24 de abril de 2002. Dispõe sobre a Língua Brasileira de Sinais Libras e dá outras providências. Disponível em: <http://www.planalto.gov.br/ccivil_03/leis/2002/110436.htm> Acesso em: 11 jul. 2018.

BRASIL. Decreto n. 5.626 de 22 de novembro de 2005. Regulamenta a Lei n. 10.436, de 24 de abril de 2002, que dispõe sobre a Língua Brasileira de Sinais - Libras, e o art. 18 da Lei n. 10.098, de 19 de dezembro de 2000. Disponível em: <http://www.planalto.gov.br/ccivil_03/_Ato2004-2006/2005/Decreto/D5626.htm> Acesso em: 11 jul. 2018.

CHOMSKY, N. Reflexões sobre a linguagem. São Paulo: Martins Fontes, 1975.

E seu nome é Jonas. And your name is Jonah (Original). Direção de Richard "Dick" Michaels. Estados Unidos da América. 1979. (100 min).

FERREIRA-BRITO, L. Por uma gramática línguas de sinais. Rio de Janeiro: Tempo Brasileiro, 1995.

FREIRE, P. Pedagogia da autonomia: saberes necessários à prática educativa. Rio de Janeiro: Paz e Terra, 1997.

GESSER, A. LIBRAS? Que língua é essa?: Crenças e preconceitos em torno da língua de sinais e da realidade surda. São Paulo: Parábola, 2009. 


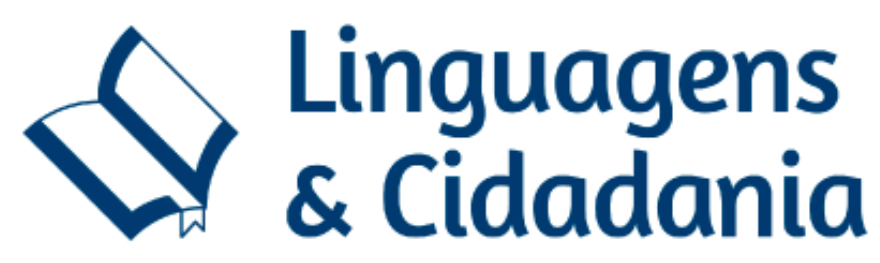

LYONS, J. Linguagem e linguística: uma introdução. Rio de Janeiro: LTC, 1987.

MARQUES, M. L. A formação do professor para educação de surdos. XII EDUCERE, Curitiba, v. 12, 2017, p. 2100-2119.

PERLIN, G. T. T. O lugar da cultura surda. In: THOMA, A. da S.: LOPES, M. C. A invenção da surdez: cultura, alteridade, identidade e diferença no campo da educação. Santa Cruz do Sul: Educnis, 2004.

SAUSSURE, F. de. Curso de linguística Geral. 27. edição. Organizado e editado por Charles Bally e Albert Sechehaye. Tradução de Antônio Chelini, José Paulo Paes e Izidoro Blikstein. São Paulo: Cultrix, [1916] 2006.

STOKOE, W. Sign and Culture: A Reader for Students of American Sign Language. Silver Spring: Listok Press, 1960.

STROBEL, K. As imagens do outro sobre a cultura surda. Florianópolis: Ed. da UFSC, 2008.

TICKS, L. K. "O que eu faço e o que eu digo que faço": a metaconsciência de professoras de inglês sobre teorias de aprendizagem. Vidya, Santa Maria, v. 28, 2009.

VYGOTSKY, L. S. Pensamento e linguagem. São Paulo: Martins Fontes, 1987. 